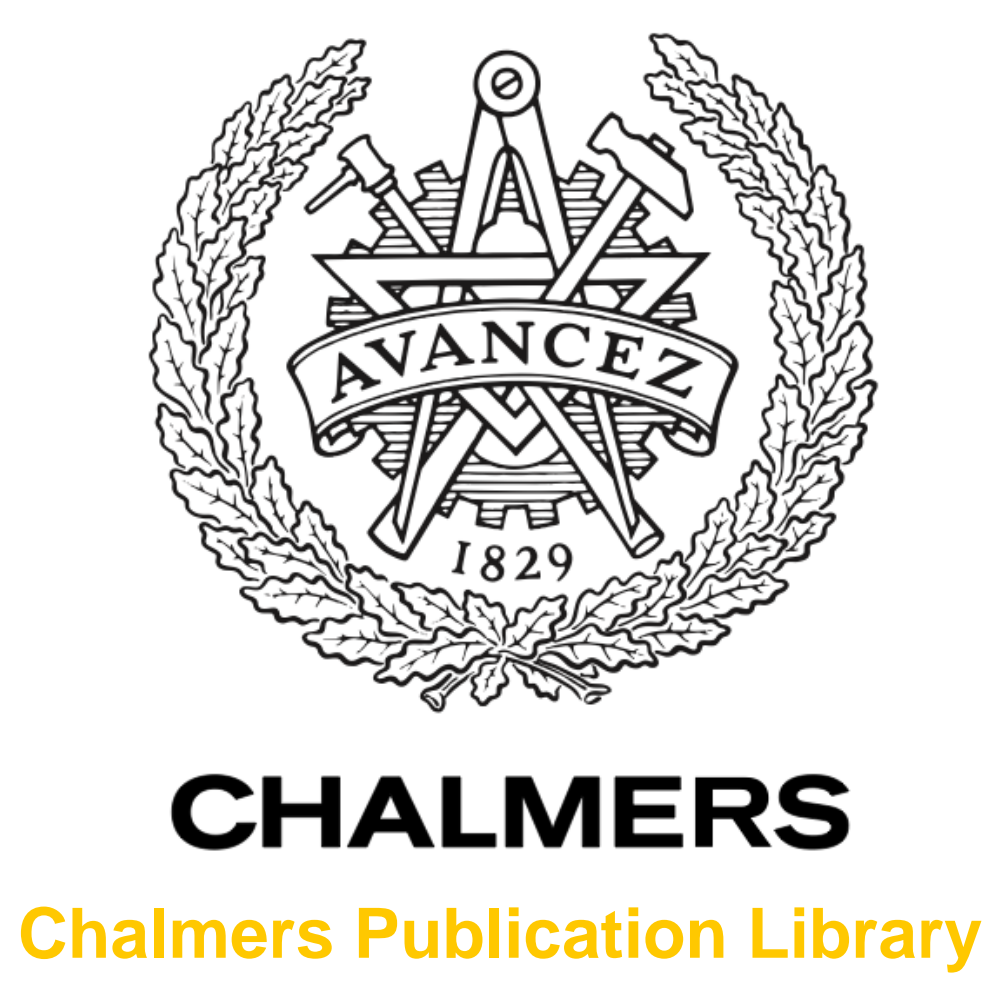

\title{
Covercrete with hybrid functions - A novel approach to durable reinforced concrete structures
}

This document has been downloaded from Chalmers Publication Library (CPL). It is the author's version of a work that was accepted for publication in:

Materials and corrosion - Werkstoffe und Korrosion (ISSN: 0947-5117)

Citation for the published paper:

Tang, L. ; Zhang, E. ; Fu, Y. et al. (2012) "Covercrete with hybrid functions - A novel approach to durable reinforced concrete structures". Materials and corrosion - Werkstoffe und Korrosion, vol. 63(12), pp. 1119-1126.

http://dx.doi.org/10.1002/maco.201206723

Downloaded from: http://publications.lib.chalmers.se/publication/168731

Notice: Changes introduced as a result of publishing processes such as copy-editing and formatting may not be reflected in this document. For a definitive version of this work, please refer to the published source. Please note that access to the published version might require a subscription.

Chalmers Publication Library (CPL) offers the possibility of retrieving research publications produced at Chalmers University of Technology. It covers all types of publications: articles, dissertations, licentiate theses, masters theses, conference papers, reports etc. Since 2006 it is the official tool for Chalmers official publication statistics. To ensure that Chalmers research results are disseminated as widely as possible, an Open Access Policy has been adopted.

The CPL service is administrated and maintained by Chalmers Library. 


\title{
Covercrete with hybrid functions - A novel approach to durable reinforced concrete structures
}

\section{Dedicated to Professor Dr. Bernhard Elsener on the occasion of his 60th birthday.}

\author{
L. Tang*, E. Q. Zhang, Y. Fu, B. Schouenborg and J. E. Lindqvist
}

Due to the corrosion of steel in reinforced concrete structures, the concrete with low water-cement ratio $(w / c)$, high cement content, and large cover thickness is conventionally used for prolonging the passivation period of steel. Obviously, this conventional approach to durable concrete structures is at the sacrifice of more $\mathrm{CO}_{2}$ emission and natural resources through consuming higher amount of cement and more constituent materials, which is against sustainability. By placing an economically affordable conductive mesh made of carbon fiber or conductive polymer fiber in the near surface zone of concrete acting as anode we can build up a cathodic prevention system with intermittent low current density supplied by, e.g., the solar cells. In such a way, the aggressive negative ions such as $\mathrm{Cl}^{-}, \mathrm{CO}_{3}^{2-}$, and $\mathrm{SO}_{4}^{2-}$ can be stopped near the cathodic (steel) zone. Thus the reinforcement steel is prevented from corrosion even in the concrete with relatively high $w / c$ and small cover thickness. This conductive mesh functions not only as electrode, but also as surface reinforcement to prevent concrete surface from cracking. Therefore, this new type of covercrete has hybrid functions. This paper presents the theoretical analysis of feasibility of this approach and discusses the potential durability problems and possible solutions to the potential problems.

\section{Introduction}

Concrete is the most widely consumed construction material in the world. Chloride induced corrosion of reinforcement steel is still a severe durability problem for reinforced concrete structures [1], which has very important economic and social consequences due to the need for diverting resources for repairing damaged structures and sometimes the need to close the facility for carrying out the repair work. These maintenance and rehabilitation works have a significant impact on the environment. Although cathodic protection techniques

\footnotetext{
L. Tang, E. Q. Zhang

Chalmers University of Technology, SE-412 96 Gothenburg (Sweden)

E-mail: tang.luping@chalmers.se

Y. Fu

KTH Royal Institute of Technology, SE-106 91 Stockholm (Sweden)

B. Schouenborg, J. E. Lindquist

CBI Swedish Cement and Concrete Research Institute, c/o SP, Box 857, SE-501 15 Borås (Sweden)
}

have been used in reinforced concrete structures for mitigating the corrosion problem since 1970s [2], application of such techniques is still met with considerable resistance [3]. Conventionally, to prevent reinforcement from corrosion, low water-cement ratio $(w / c)$ is used in concrete for reducing ingress rate of aggressive substances and large cover thickness is designed for prolonging the time for aggressive substances to reach the reinforcement steel under the specified service life. To have fresh concrete workable with low $w / c$, high cement content or superplasticizer has to be used. It is obvious that high cement content implies high $\mathrm{CO}_{2}$ emission with regard to the production of cement. From the structural point of view, in many cases it is unnecessary to have very high strength. On the other hand, high strength concrete often reveals a relatively large spread in concrete quality $[4,5]$. Large cover thickness simply implies more volume of concrete materials. Obviously, this conventional approach to durable concrete structures is at the sacrifice of more $\mathrm{CO}_{2}$ emission and natural resources though consuming higher amount of cement and more constituent materials, which is against the fundamental ideas of sustainability. Although the use of industrial by-products, such as fly ash and slag, as pozzolanic additions to partially replace Portland cement in the 
mixes is a usual approach to reduce the cement content in concrete, this approach is, however, strongly dependent on the availability of by-products with qualified pozzolanic properties. Due to more strict environmental regulations, coal power plants are reducing, implying less and less availability of fly ash in the future. With the technical development of steel industry, the quality of slag may vary more and more. Therefore, new and more sustainable approaches are needed for corrosion prevention or protection of reinforcement steel in concrete. Because concrete is porous and contains electrolytic pore solution, using the principle of electrochemical migration in porous concrete is probably a more active way for prevention of reinforcement in concrete from corrosion. In such a way the properties of concrete with high $w / c$ may better be utilized. This paper presents the theoretical analysis of feasibility of this approach and discusses the potential durability problems and possible solutions to the potential problems.

\section{Reappraisal of capillary pores in concrete}

Concrete is porous and the pore solution in concrete contains various types of ions, especially hydroxide ions which are very conductive due to their high mobility. Conventionally, the capillary pores in concrete are often negatively appraised, mainly due to the fact that the capillary pores provide permeable paths to ingress of aggressive substances such as carbon dioxides, chlorides, sulphates, etc., and leaching of $\mathrm{Ca}(\mathrm{OH})_{2}$. Watercement ratio $(w / c)$ is directly related to the capillary porosity of concrete. To reduce capillary porosity, low $w / c$ is used in concrete production. Although the use of low $w / c$ apparently reduces the permeability of concrete, it also causes a number of negative effects, as listed in Table 1.

From Table 1, it can be seen that, except for permeability and strength, the concrete with high $w / c$ has even more advantages than that with low $w / c$. The strength is of course one of the most important mechanical properties of a construction material. In many cases, the strength of concrete with moderately high $w / c$ (0.5-0.6) is sufficient for general construction purposes.

High permeability is not always negative. Carbonation in fact improves properties of Portland cement concrete with increased strength and frost resistance [6]. Cement production emits $\mathrm{CO}_{2}$ by turning calcium carbonate to calcium oxides, while carbonation of concrete consumes $\mathrm{CO}_{2}$ to return hydrated calcium oxides to calcium carbonate, resulting in zero-emission of $\mathrm{CO}_{2}$ if concrete is completely carbonated. Therefore, carbonation of concrete is positive to sustainable development of society. High permeability promotes the carbonation process.
Chlorides in water under normal conditions are not harmful to concrete, but can induce pitting corrosion of reinforcement steel.

Leaching of calcium hydroxides can be a problem if concrete is in long-term contact with running water. The process of leaching is, however, relatively slow and normally will not be as such an extent that can significantly damage concrete structures with a service life of 50-100 years [7].

Regarding the frost durability, air entraining is a more effective way than decreasing $w / c[8]$.

Chemical deterioration is an important durability issue which will be dealt with in the further research project. Alkalisilica reaction (ASR) is a main concern because the increased porosity and permeability due to a high $w / c$ may enhance potential ASR, but on the other hand a higher porosity has the capability to contain higher amounts of ASR gel before any structural damage occurs to the concrete.

In summary, if there is no problem of reinforcement corrosion and chemical deterioration is properly mitigated, the concrete with high $w / c$ would have more advantages.

\section{New type of covercrete}

Because of the big problems of steel corrosion in reinforced concrete structures, many research efforts worldwide were made on how to prevent or protect reinforcement steel in concrete from corrosion [9]. Studies of carbonation, chloride transport, chloride threshold values, reinforcement corrosion, cathodic protection, stainless steel reinforcement, glass fiber reinforcement, etc., are some examples of research topics in this area. In Sweden, owing to the fact of long coast lines and intensive use of de-icing salts in the winter, great efforts have been made on chloride transport and reinforcement corrosion [10-12]. Consequently, as a defensive measure, the limits of maximum water-cement ratio and minimum cover thickness of concrete are specified in various national codes in order to assure the durability of expensive infrastructures mainly with regard to damage due to corrosion of steel. Although there are some offensive measures using, e.g., pozzolanic additions from expensive silica fume to relatively cheap industrial by-products fly ash, slag, etc., their durability is still a hot research topic.

Another technique - cathodic protection - has been applied to reinforced concrete structures since $1970 \mathrm{~s}$ [2, 13, 14], but to a limited extent due to relatively high costs in both installation and maintenance, as well as "psychological factors" as Polder and Peelen [3] recently pointed out.

Table 1. Comparison between concretes with low and high water-cement ratios

\begin{tabular}{lccl}
\hline Factor & Low $w / c$ & High $w / c$ & \multicolumn{1}{c}{ Comments } \\
\hline Cement content & High $(-)$ & Low $(+)$ & "Low" means less $\mathrm{CO}_{2}$ emission \\
Permeability & Low $(+/-)$ & High $(-/+)$ & "+" or "-" depends on exposure environment \\
Strength & High $(+/-)$ & Low $(-/+)$ & "+" or "-" depends on load bearing requirement \\
Shrinkage & Low $(+)$ & High $(-)$ & "Low" means less risk for cracking \\
Inhomogeneity & High $(-)$ & Low $(+)$ & "Low" means better homogeneity regarding mechanical and physical properties \\
Fire resistance & Poor $(-)$ & Good $(+)$ & "Good" means less risk for spalling under fire \\
\hline
\end{tabular}


With the development of photovoltaic technology, solar cells nowadays become more and more affordable for general uses. Recently, the development of solar cells based on polymer and nano-particles [15] is in good progress and can be expected for practical applications at an affordable price in the near future. Thus by placing a conductive mesh in the near surface zone of concrete acting as one electrode and taking reinforcement steel network as the other electrode, together with the pore solution as electrolyte, we can form a battery-like covercrete which can be charged by the solar cells, small wind turbines, or wave turbines, as illustrated in Fig. 1. Under the charging process, the reinforcement functions as cathode where hydroxides are produced and all other negative ions, such as $\mathrm{Cl}^{-}, \mathrm{CO}_{3}^{2-}$, and $\mathrm{SO}_{4}^{2-}$, are repelled towards the anode - the conductive mesh near the surface of concrete. In this way, the aggressive negative ions have less chance to reach the steel bars and can be stopped in the near surface zone. Thus the reinforcement steel is prevented from corrosion even in the concrete with relatively high $w / c$ and small cover thickness.

The conductive mesh can be made of carbon fibre which is conductive and durable with good mechanical properties. Recently, some types of carbon fiber mesh, e.g., SIGRATEX Grid, C-Grid, StoFRP Grid, etc., have become commercially available at affordable prices for strengthening concrete and reducing cracking. If it is proven that glass fiber fabrics, or alike, can be coated with high conductive polymers at affordable prices, the costs of conductive mesh can be further reduced. This

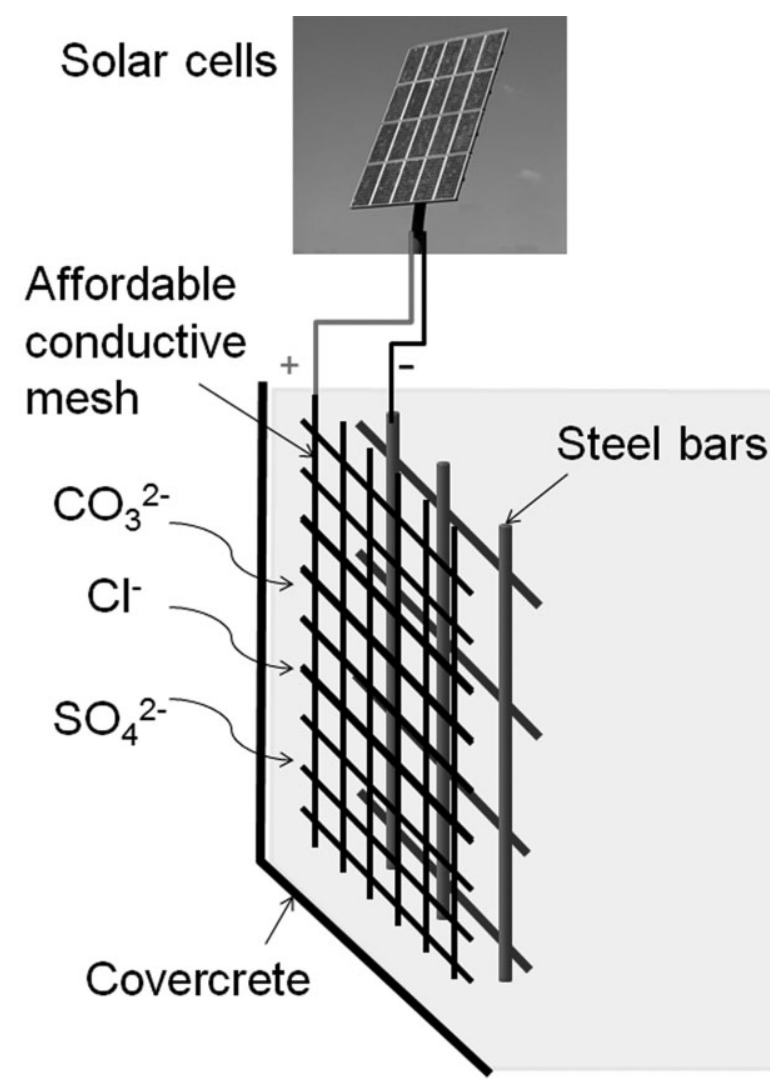

Figure 1. Illustration of the new type of covercrete with intermittent corrosion prevention conductive mesh functions not only as electrode, but also as surface reinforcement to prevent concrete surface from cracking due to drying shrinkage.

Obviously, this new type of covercrete has hybrid functions, i.e., prevention/protection of reinforcement from corrosion and prevention of concrete surface from cracking. The mesh can be installed in combination with the reinforcement spacers before concrete casting. Therefore, this type of covercrete can be used primarily in new structures and, if proven economically feasible, also in old structures where no significant corrosion of reinforcement occurs.

\section{Difference from conventional cathodic protection}

As mentioned previously, cathodic protection techniques have been applied in reinforced concrete structures $[2,13,14]$ and some basic guidelines and application practices are available, e.g., in the report by Bennet et al. [16] and also in the recent standard EN ISO 12696:2012. In a conventional active cathodic protection system expensive titanium meshes are used as anode for carrying a cathodic current at a density of $10-20 \mathrm{~mA} / \mathrm{m}^{2}$ for corroding reinforced structures under a severe environment, resulting in acid accumulation near the anode (titanium meshes). This is the main reason why the service life of a conventional cathodic protection system is normally limited to 20-30 years, although there are also examples in practice that the average running current density of the cathodic protection system is $<10 \mathrm{~mA} / \mathrm{m}^{2}$ in the long term $[14,17]$, depending on the severity of environment and the corroding condition of reinforcement steel.

As an important difference, the new covercrete involves the use of intermittent cathodic current with relatively low density (average current density $\leq 5 \mathrm{~mA} / \mathrm{m}^{2}$ through proper design of concrete cover and anode system, as will be demonstrated later). Therefore, meshes with lower conductivity than titanium, such as carbon fiber and glass fiber with conductive coatings, can be used as anode, which is relatively inexpensive and should be affordable. Significant increase of service life of such a new system should be expected due to low current density (low evolution of gases and low accumulation of acid). This will, of course, be examined and assured through further research work.

Conventional cathodic protection needs a careful regulation of current density with continuous power supply from the main line, which is not always accessible in the field structures. If natural solar, wind, or wave energy is used for power supply, the system is under intermittent cathodic protection, whose feasibility has been investigated by Glass et al. [18]. Because the rate of ionic migration under the external electrical field is much faster than the rate of ionic diffusion under the current intermittent period, it should be possible by proper design of the system to allow a long period (several days) of intermittent for eventual maintenance (replacement or repair of damaged chargers or cables). This implies that the new covercrete requires less maintenance when compared with conventional cathodic protection systems. 


\section{Theoretical analysis of feasibility}

\subsection{Migration potential}

It is well described in the electrochemical textbook (e.g., Newman and Thomas-Alyea [19]) that, under a gradient of external electrical potential, the cations, such as $\mathrm{Na}^{+}, \mathrm{K}^{+}, \mathrm{Ca}^{2+}$, etc., in the pore solution, will move towards the cathode whilst the anions, such as $\mathrm{OH}^{-}, \mathrm{Cl}^{-}, \mathrm{CO}_{3}^{2-}$, and $\mathrm{SO}_{4}^{2-}$ will move toward the anode. The actual movement of ionic species can be described by the Nernst-Planck equation:

$J_{i}=-D_{i} \frac{\partial c_{i}}{\partial x}-c_{i} D_{i} \frac{z_{i} F}{R T} \cdot \frac{\partial \phi}{\partial x}$

where $J$ is the flux of ions, $D$ denotes the diffusion coefficient, $c$ is the molar concentration, $R$ is the gas constant, $T$ is the absolute temperature, $x$ is the distance, $z$ is the valence of ions, $F$ is the Faraday constant, and $\phi$ is the electrical potential including both the so called counter electrical potential due to different mobilities between anions and cations and the imposed external electrical potential across the anode and the cathode. The subscript $i$ represents specific type of ions. In the right side of Equation (1) the first term describes diffusion, whilst the second term describes migration process. Under the natural conditions, chloride ions in the seawater or deicing salt will diffuse into concrete due to the gradient of chloride concentration. It is possible to keep the net flux of chloride ions zero or negative (backwards movement), i.e., $J \leq 0$ in Equation (1), by applying a proper external electrical field against the concentration gradient, that is,

$c_{i} \cdot \frac{\left|z_{i}\right| F}{R T} \cdot \frac{\partial \phi}{\partial x} \geq \frac{\partial c_{i}}{\partial x}$ into

After rearrangement and simplification Equation (2) turns

$d \phi \geq \frac{R T}{\left|z_{i}\right| F} \cdot \frac{d c_{i}}{c_{i}}$

Because $R=8.314 \mathrm{~J} /(\mathrm{mol} \mathrm{K}), F=96485 \mathrm{~J} /(\mathrm{mol} \mathrm{V})$, under the normal temperature $T \approx 293 \mathrm{~K}$, integrating the above equation yields

$\Delta \phi \geq \frac{R T}{\left|z_{i}\right| F} \cdot \ln \frac{c_{i a}}{c_{i c}}=\frac{0.025}{\left|z_{i}\right|} \cdot \ln \frac{c_{i a}}{c_{i c}}$

where $c_{i a}$ and $c_{i c}$ denote the $i$-th ion concentration closer to anode and cathode, respectively. Regarding chloride ingress $\left(\left|z_{\mathrm{Cl}}\right|=1\right)$, we can take $c_{i a}$ equal to the chloride concentration in the near surface zone of concrete and $c_{i c}$ equal to a value lower than the conventional chloride threshold concentration for corrosion of steel in the concrete. In normal cases the ratio $c_{i a} / c_{i c}$ is about 10 , if, e.g., $c_{i a}$ is $0.5 \mathrm{M}$ in the seawater and $c_{i c}$ is $0.05 \mathrm{M}$ in the pore solution $\left(\mathrm{pH}>13\right.$, corresponding to $\left[\mathrm{OH}^{-}\right]>0.1 \mathrm{M}$ ), resulting in a potential difference of $58 \mathrm{mV}$. According to Zhang and
Buenfeld [20], the membrane potential for OPC mortar with water-cement ratio $w / c 0.45$ in $\mathrm{NaCl}$ solutions of concentrations $1 \mathrm{M}$ and $0.1 \mathrm{M}$ is $22-35 \mathrm{mV}$, which could be an estimate of counter electrical potential. Thus an external potential of 18$35 \mathrm{mV}$ may be sufficient to stop or hinder chloride ingress in the concrete cover layer. It should be noted that the hydroxides produced on the cathodic side may increase the chloride threshold concentration and reduce the actual ratio $c_{i a} / c_{i c}$. Thus the external potential needed to stop chloride ingress will be even less.

\subsection{Migration current}

Under a certain gradient of external electrical potential, the migration current is the sum of ions moving in the pore solution, that is,

$I=A F \sum_{j} z_{j} J_{j}=A F \sum_{j} z_{j}\left(-D_{j} \frac{\partial c_{j}}{\partial x}-c_{j} D_{j} \frac{z_{j} F}{R T} \cdot \frac{\partial \phi}{\partial x}\right)$

where $I$ is the migration current and $A$ is the cross-sectional area of concrete. The subscript $j$ denotes various types of ions. Clearly, the migration current is dependent on the concentration and diffusivity of various ions in the pore solution, which is not so easy to be quantified. Combining Equations (5) and (1) we obtain the following equation:

$J_{i}=-D_{i} \frac{\partial c_{i}}{\partial x}+\frac{D_{i} z_{i} c_{i}\left(\sum_{j} D_{j} z_{j} \frac{\partial c_{j}}{\partial x}+\frac{I}{A F}\right)}{\sum_{j} D_{j} z_{j}^{2} c_{j}}$

The above equation has already been used by, e.g., Truc, et al. [21]. If the secondary order of differential of the electrical potential is negligible, that is, $\partial^{2} \phi / \partial x^{2}=0$, the non-steady state transport process can be expressed as

$\frac{\partial c_{i}}{\partial t}=-\frac{\partial J_{i}}{\partial x}=D_{i} \frac{\partial^{2} c_{i}}{\partial x^{2}}-\frac{D_{i} z_{i}\left(\sum_{j} D_{j} z_{j} \frac{\partial c_{j}}{\partial x}+\frac{I}{A F}\right)}{\sum_{j} D_{j} z_{j}^{2} c_{j}} \cdot \frac{\partial c_{i}}{\partial x}$

Obviously, numerical modeling has to be employed to simulate the multispecies diffusion and migration.

\subsection{Chemical reactions on the electrodes}

If the non-corrosive material is used as anode, the chemical reaction on the anode will be

$2 \mathrm{H}_{2} \mathrm{O} \rightarrow \mathrm{O}_{2} \uparrow+4 \mathrm{H}^{+}+4 e^{-}$

Under the aerobic conditions, the cathodic reaction is

$\mathrm{O}_{2}+2 \mathrm{H}_{2} \mathrm{O}+4 e^{-} \rightarrow 4 \mathrm{OH}^{-}$ 
If the availability of oxygen is limited inside the concrete, the reaction on the cathode (reinforcement steel) will be

$2 \mathrm{H}_{2} \mathrm{O}+2 e^{-} \rightarrow \mathrm{H}_{2} \uparrow+2 \mathrm{OH}^{-}$

According to Faraday's law the increase in concentration of hydrogen and hydroxide ions on the anode and cathode, respectively, can be expressed as

$\Delta c_{\mathrm{OH}}=\Delta c_{\mathrm{H}^{+}}=\frac{I}{V F} \cdot \Delta t$

where $V$ is the volume of solution.

\subsection{Numerical simulation of multispecies diffusion and migration}

In a cathodic protection or prevention system a certain density of current is imposed to keep the reinforcement steel in a range of values below the protection or pitting potential, respectively [2]. It is, however, difficult to predict the potential of reinforcement steel in concrete due to many influencing factors. Therefore, the numerical simulation will be focused on the changes in the exposure environment, that is, the ionic concentrations near the reinforcement steel. Truc et al. [21] has proposed a numerical model for multispecies diffusion and migration under the conditions of mass balance and electro-neutrality. Similar models have been used by other researchers, e.g., Samson and Marchand [22]. Recently we implemented this model in a MS Excel workbook for an easy simulation of multispecies diffusion and migration. In the simulation five types of ions were considered, that is, $\mathrm{K}^{+}, \mathrm{Na}^{+}$, and $\mathrm{Ca}^{2+}$ as cations, and $\mathrm{OH}^{-}$and $\mathrm{Cl}^{-}$as anions. A constant current density of $0,2,5$, and $10 \mathrm{~mA} / \mathrm{m}^{2}$ was applied across $35 \mathrm{~mm}$ concrete layer with a water-accessible porosity of $15 \%$ (for current paths in the calculation) and a chloride diffusion coefficient of $D_{\mathrm{Cl}}=20 \times 10^{-12} \mathrm{~m}^{2} / \mathrm{s}$ in the pore solution, which is $1 / 100$ of the diffusion coefficient in the bulk solution, roughly corresponded to a concrete with $w / c 0.55-0.6$ according to the model suggested by Bentz and Garboczi [23]. The diffusion coefficients of other ions are proportional to $D_{\mathrm{Cl}}$ with the same ratio as in the bulk solution, based on the ionic mobility data in the textbook by Atkins [24], as listed in Table 2, where the boundary and initial conditions are also listed. Because the anode side is close to the bulk exposure solution and has better ability to exchange the ions with the exposure solution, the volume of the anode side was, therefore, assumed as $10 \mathrm{~m}^{3}$ so as to keep relatively constant ionic concentrations on this side. Whilst the exchange of ions on the cathode side is limited to the surrounding concrete and thus the volume of the cathode side was assumed as $0.1 \mathrm{~m}^{3}$, also $1 / 100$ of the volume of the anode side. In this simulation the effect of chloride binding was ignored, because in the long term this effect will disappear anyway. It was also assumed that the Portlandite in the cement paste is sufficient to keep the initial calcium concentration of $23 \mathrm{~mol} / \mathrm{m}^{3}$, as in the saturated lime water. Similar to the numerical simulation by Truc et al. [21], the hydroxide ions were used as compensator to hold the condition of electro-neutrality, that is, the concentration changes in $\mathrm{OH}^{-}$at each time increment were based on the changes of other ions in the solution but not on its own flux. This is reasonable because the diffusion coefficient of $\mathrm{OH}^{-}$is larger than double as much as the other ions in the pore solution. The detailed work of modeling and simulation will be published elsewhere. Some of the preliminary results from the numerical simulation are shown in Figs. 2 and 3.

As expected, the imposed current significantly separated the distributions of sodium and chloride ions and made the cathodic side (reinforcement steel) more alkaline, as shown in Fig. 2. The significance of changes is proportional to the imposed current density. The results in Fig. 3 show that, without imposed electrical current $\left(i=0 \mathrm{~mA} / \mathrm{m}^{2}\right)$, the chloride ions increase and hydroxide ions decrease around the steel surface. The threshold concentration of $\left[\mathrm{Cl}^{-}\right] /\left[\mathrm{OH}^{-}\right]=0.6[25]$ could be reached after 11 years. With an imposed current density of $i=10 \mathrm{~mA} / \mathrm{m}^{2}$, the chloride ions could almost be stopped out of the cathode, but the alkalinity around the cathode could significantly increase. At a current density of $i=5 \mathrm{~mA} / \mathrm{m}^{2}$, the chloride ions would increase to a certain level, whilst the hydroxide ions also increased. The ratio of $\left[\mathrm{Cl}^{-}\right] /\left[\mathrm{OH}^{-}\right]$would be always less than the threshold value 0.6 (maximum 0.52 at the exposure time of 43 years in the example). This means that the imposed current density of $5 \mathrm{~mA} / \mathrm{m}^{2}$ might be sufficient to prevent the reinforcement steel from active corrosion. At a low current density of $i=2 \mathrm{~mA} / \mathrm{m}^{2}$, the ratio of $\left[\mathrm{Cl}^{-}\right] /\left[\mathrm{OH}^{-}\right]$will reach the threshold value 0.6 after 15 years but will never exceed 1.8. It is known that under the cathodic polarization the threshold value for initiating corrosion may increase by almost one order of magnitude [2]. If it is proven that this small current density can successfully shift the potential of steel by $100 \mathrm{mV}$ to the negative side, this low current density is more beneficial for the new type of covercrete to prevent corrosion of the reinforcement steel in the structures.

It should be noted that the constant current used in the simulation can be taken as an integrated or average current under the intermittent power supply by, e.g., solar cells. In the actual design of the power supply and current regulation system, the current level should be higher in order to reach the integrated level. This is, of course, dependent on the regional solar intensity.

Table 2. Initial conditions and diffusion coefficients used in the simulation

\begin{tabular}{lcc}
\hline Anode side & Concrete layer of $35 \mathrm{~mm}$ & Cathode side \\
\hline $\mathrm{NaCl}: 500 \mathrm{~mol} / \mathrm{m}^{3}$ & $\mathrm{KOH}: 250 \mathrm{~mol} / \mathrm{m}^{3}$ & $\mathrm{KOH}: 250 \mathrm{~mol} / \mathrm{m}^{3}$ \\
$\mathrm{Ca}(\mathrm{OH})_{2}: 23 \mathrm{~mol} / \mathrm{m}^{3}$ & $\mathrm{NaOH}: 50 \mathrm{~mol} / \mathrm{m}^{3}$ & $\mathrm{NaOH}: 50 \mathrm{~mol} / \mathrm{m}^{3}$ \\
With the cell volume of $10 \mathrm{~m}^{3} \quad \mathrm{Ca}(\mathrm{OH})_{2}: 23 \mathrm{~mol} / \mathrm{m}^{3}$ with cross-sectional area of $1 \mathrm{~m}^{2}$ & $\mathrm{Ca}(\mathrm{OH})_{2}: 23 \mathrm{~mol} / \mathrm{m}^{3}$ with the cell volume of $0.1 \mathrm{~m} \mathrm{~m}^{3}$ \\
Assumed ion diffusion coefficient in the pore solution, $\times 10^{-12} \mathrm{~m}^{2} / \mathrm{s}$ & \\
$D_{\mathrm{Cl}}=20.3 ; D_{\mathrm{Na}}=13.3 ; D_{\mathrm{K}}=19.6 ; D_{\mathrm{Ca}}=7.72 ;$ and $D_{\mathrm{OH}}=53$ &
\end{tabular}

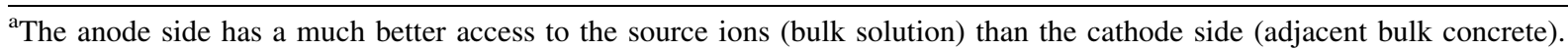



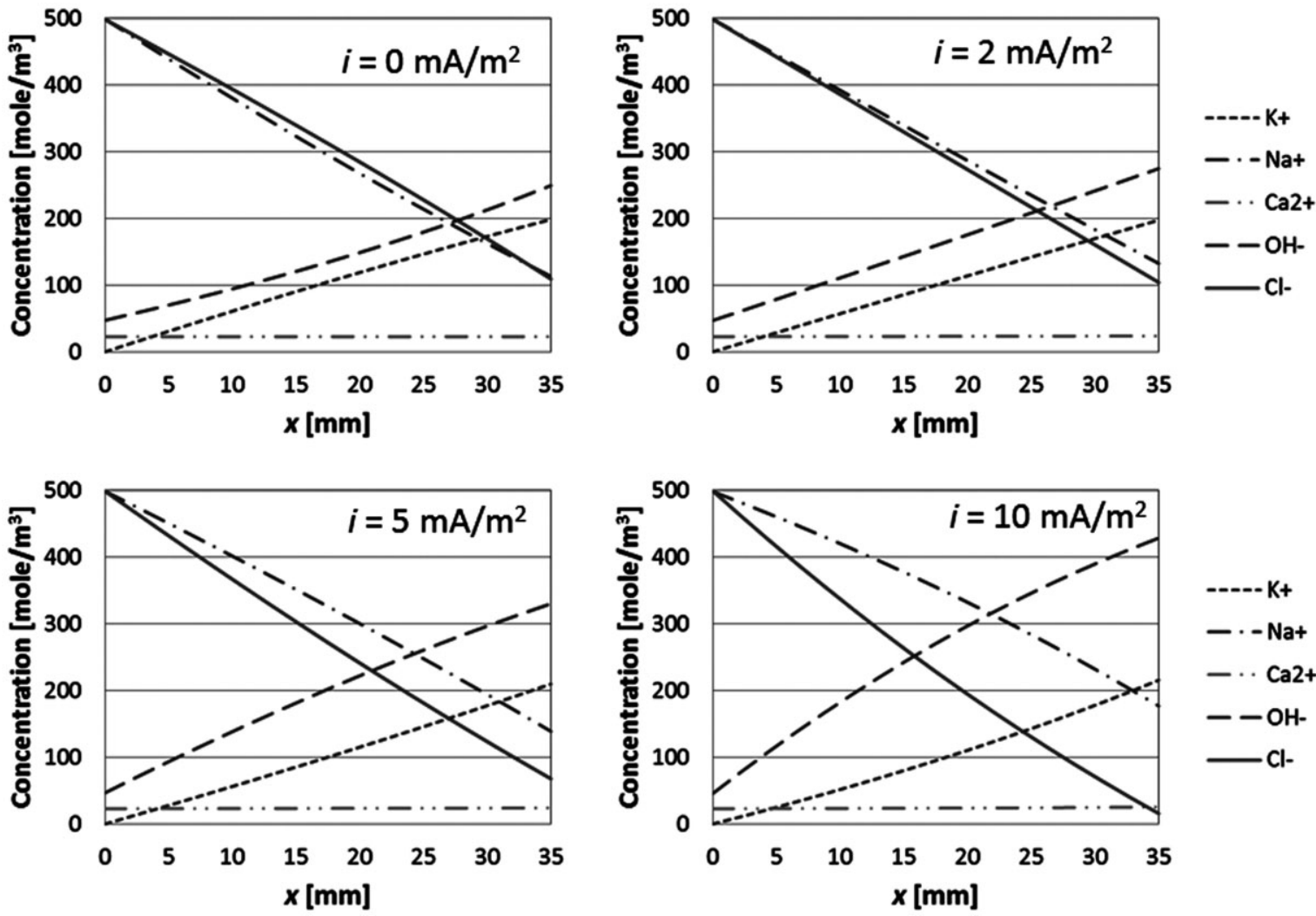

Figure 2. Simulated distributions of ions in the covercrete after 10 years' exposure
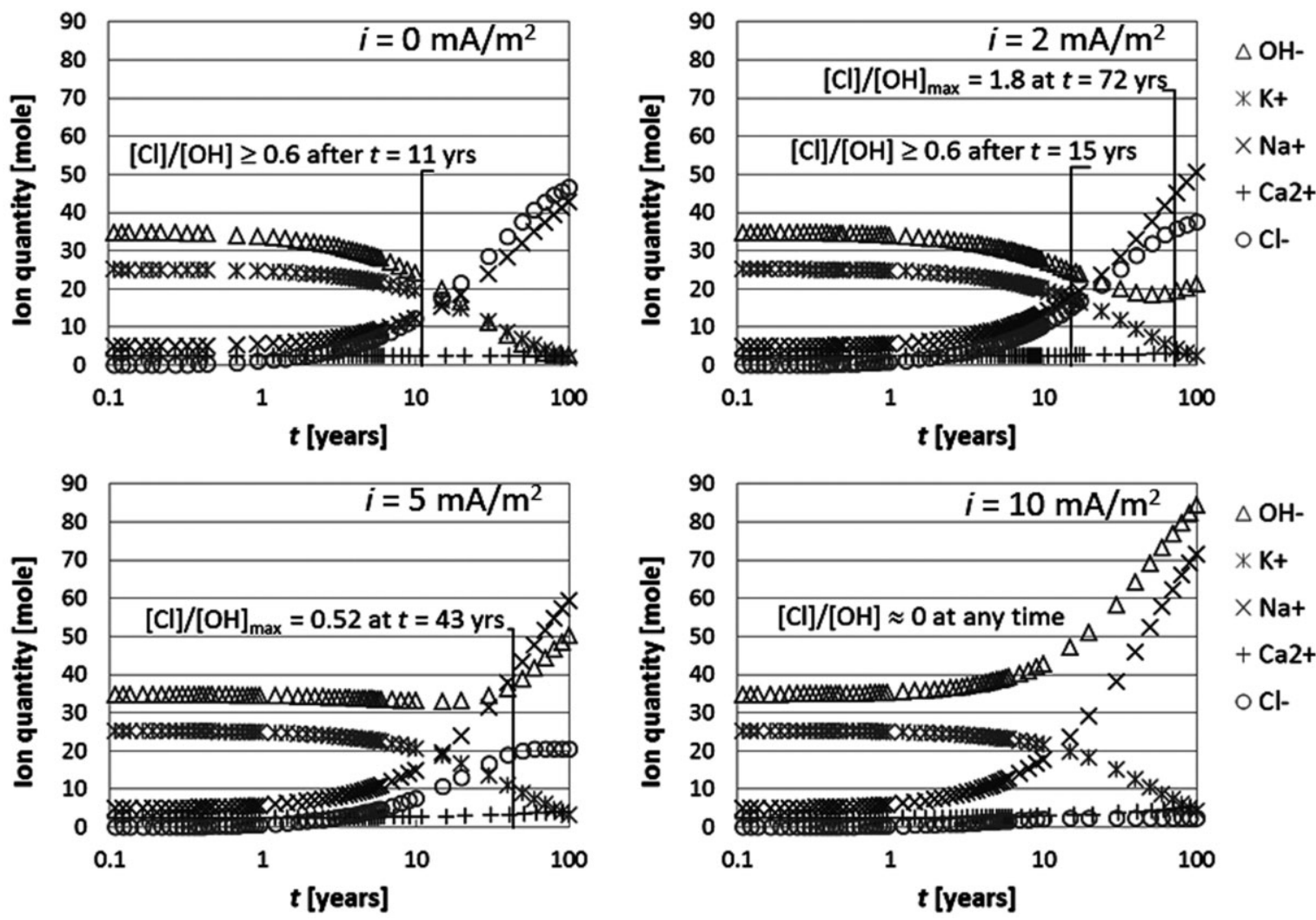

Figure 3. Accumulated quantity of ions in the cathodic cell 
If the initiation of corrosion is taken as the end of service life, the concrete in the above example would have a service life of some 10 years without cathodic prevention system. The above simulations demonstrates that a small average current density could effectively prevent the steel from corrosion and extend the service life up to over 100 years if no any other deterioration of concrete occurs. With such a prevention system, it is possible to build a marine concrete structure for long service life without dramatically reduce water-cement ratio or increase cover thickness.

\section{Possible problems and solutions}

\subsection{Gas evolution}

It is shown from Equation (8) that oxygen gas will always be produced on the anode side. If the gas around the electrode cannot be released by dissolving into the pore solution or permeating through the empty channels of pores, the increased gas pressure may locally damage the bonding between concrete and the electrode. As a consequence, the layer of concrete-anode may be impaired. On the other hand, the increased pressure will also increase the release of gas. There exists a pressure to balance the gas production and release. It could be possible to design the concrete with sufficient permeability for the gas release.

\subsection{Alkali-silica reaction (ASR)}

As shown in Fig. 3, due to the effect of electrical migration, the sodium ions from the seawater will be accumulated on the cathode side causing high alkalinity. There is a risk of ASR if the aggregate contains a certain amount of unstable poorly crystallized hydrous silica. Although the maximum amount of reactive silica in aggregate to be used in the concrete structures has been specified in the current standards, further experimental investigation is needed to verify the safety with regard to ASR.

\subsection{Acidification on the anode side}

As shown in Equation (8), hydrogen ions will be produced on the anode side. These hydrogen ions are immediately neutralized by the hydroxide ions partly from the concrete and partly from the cathode side. Once the Portlandite (calcium hydroxide) in concrete near the anode is consumed out and the hydroxide ions diffused or migrated to the anode is not enough to neutralize the hydrogen ions produced due to the imposed current, the acid will be formed which can destroy the calcium-silicate-hydrate (CSH) gel around the anode, impairing the bond strength of the anode mesh. If the main purpose of the mesh is for supplying electrical connectivity but not for reinforcement, the reduction of bond strength may not be a problem to the continuation of cathodic prevention system. On the other hand, the use of high alkaline cement may also be possible to extend the service life of the anode mesh. Some preliminary modeling work by Peelen et al. [26] shows that acidification on the anode side is strongly dependent on the current density, concrete compositions, and exposure conditions. It is still unclear which mechanisms determine anode durability in practice [26].

\section{Concluding remarks}

With the development of solar cells and conductive fiber meshes, a new type of covercrete with hybrid functions can be built up to cathodically prevent reinforcement steel in concrete from corrosion and mechanically prevent concrete surface from cracking. The numerical simulation results from the model of multispecies diffusion-migration has demonstrated that it is feasible to prevent reinforcement steel in concrete from corrosion by imposing intermittent cathodic current at a relatively low average current density (e.g., $\leq 5 \mathrm{~mA} / \mathrm{m}^{2}$ ). With this low current density the service life of the cathodic prevention system should be significantly longer than the conventional cathodic protection system, which uses higher current density $\left(10-20 \mathrm{~mA} / \mathrm{m}^{2}\right)$. Thus the troubles due to the imposed current can be reduced or even eliminated. With this new type of covercrete, the properties of concrete with high $w / c$ can be better utilized and the cover thickness can be reduced. As a consequence, cement and raw materials will be less consumed in the reinforced concrete structures.

As a summary of the above discussions, it can be seen that the feasibility of this new covercrete is high. In order to assure the durability of reinforced concrete structures, further theoretical and experimental studies are needed to improve our knowledge and understanding of the stability of cementitious hydrates and the mechanical properties of reinforcement steel under the longterm action of intermittent cathodic current, that is, the cycles of charging and discharging.

Acknowledgements: Financial supports for this work from the Swedish Research Council FORMAS (project Nos. 2010-49 and 2011-1520) are acknowledged.

\section{References}

[1] C. L. Page, Mater. Corros. 2012, 63, 1052.

[2] P. Pedeferri, Constr. Building Mater. 1996, 10, 391.

[3] R. B. Polder, W. H. A. Peelen, Mater. Corros. 2012, 63, 1147.

[4] Y.-S. Park, J.-K. Suh, Intl. J. Concr. Struct. Mater. 2008, 2, 15.

[5] D. Duthinh, Shear Strength of High-Strength Concrete Walls and Deep Beams,NISTIR 6495, National Institute of Standards and Technology, Gaithersburg, USA 2000.

[6] P. Utgenannt, PhD Thesis, Div. of Building Materials, Report TVBM-1021, Lund Inst. Techn., Lund, Sweden, 2004.

[7] N. Otsuki, H. Minagawa, S. Miyazato, T. Nishida, Proceedings of JSCE, No. 676/V-51, pp. 41-449, 2001.

[8] US Bureau of Reclamation. Investigation into the Effect of Water/Cement Ratio on the Freezing-Thawing Resistance of Non-Air and Air-Entrained Concrete, Concrete Laboratory Report No. C-810, Denver, 1955.

[9] R. Cigna, C. Andrade, U. Nürnberger, R. Polder, R. Weydert, E. Seitz, Corrosion of Steel in Reinforced Concrete Structures, Final Report of COST Action 521, ISBN 92-894-4827-X, European Communities, Brussels 2003. 
[10] K. Tuutti, Corrosion of Steel in Concrete, CBI Research fo 4:82, Swedish Cement and Concrete Research Institute, Stockholm, 1982.

[11] L. Tang, PhD Thesis, P-96:6, Dept. of Building Materials, Chalmers Uni. Tech., Gothenburg, Sweden, 1996.

[12] L. Tang, L.-O. Nilsson, P. A. M. Basheer, Resistance of Concrete to Chloride Ingress, Spon Press, London 2011.

[13] L. Bertolini, F. Bolzoni, A. Cigada, T. Pastore, P. Pedeferri, Corr. Sci. 1993, 35, 1633.

[14] L. Bertolini, F. Bolzoni, P. Pedeferri, J. Appl. Electrochemistry 1998, 28, 1321.

[15] W. U. Huynh, J. J. Dittmer, A. P. Alivisatos, Science 2002, 295, 2425.

[16] J. E. Bennet, J. J. Bartholomew, J.-B. Bushman, K. C. Clear, R. N. Kamp, W. J. Swiat, Cathodic Protection of Concrete Bridges: A Manual of Practice, SHRP-S-372, National Research Council, Washington D.C., 1993.
[17] R. B. Polder, HERON 1998, 43, 3.

[18] G. K. Glass, A. M. Hassanein, N. R. Buenfeld, Corros. Sci. 2001, 43, 1111.

[19] J. Newman, K. E. Thomas-Alyea, Electrochemical System, 3rd ed. Wiley-Interscience, New Jersey 2004.

[20] J.-Z. Zhang, N. R. Buenfeld, Cem. Concr. Res. 1997, 27, 853.

[21] O. Truc, J. P. Ollivier, M. Carcassès, Cem. Concr. Res. 2000, 30, 217.

[22] E. Samson, J. Marchand, J. Colloid Interface Sci. 1999, 215, 1.

[23] D. P. Bentz, E. J. Garboczi, Mater. Struct. 1992, 25, 523.

[24] P. W. Atkins, Physical Chemistry, 5th ed. Oxford Uni. Press, Oxford 1994.

[25] D. A. Hausmann, Mater. Prot. 1967, 6, 19.

[26] W. H. A. Peelen, R. B. Polder, E. Redaell, L. Bertolini, Mater. Corros. 2008, 59, 81.

(Received: May 31, 2012)

W6723

(Accepted: September 11, 2012) 